\title{
A PILOT STUDY OF ENERGY EFFICIENT AIR CLEANING FOR OZONE
}

\author{
Lara A. Gundel, Douglas P. Sullivan, Gregory Y. Katsapov \\ and William J. Fisk \\ Indoor Environment Department \\ Environmental Energy Technologies Division \\ Lawrence Berkeley National Laboratory \\ Berkeley, CA 94720
}

November 28, 2002

This work was supported by the Assistant Secretary for Energy Efficiency and Renewable Energy, Building Technologies Program of the U.S. Department of Energy under contract No. DE-AC03-76SF00098. 
LBNL-51836

\title{
A PILOT STUDY OF ENERGY EFFICIENT AIR CLEANING FOR OZONE
}

\author{
Lara A. Gundel, Douglas P. Sullivan, Gregory Y. Katsapov and William J. Fisk \\ Indoor Environment Department \\ Environmental Energy Technologies Division \\ Lawrence Berkeley National Laboratory \\ Berkeley, CA 94720
}

November 28, 2002

\begin{abstract}
This report explores the feasibility of energy efficient low cost ozone removal from indoor air by examining carbon-based filtration options. Several candidate carbon-based materials and configurations were assessed by review of previous work and performance calculations. In addition, a laboratory pilot study was undertaken with the material that showed the most potential promise. This material was a commercially available filter that contained a thin layer of small activated carbon particles in a pleated configuration. For three months ozone $(113 \pm 13 \mathrm{ppm})$ in particle-filtered ambient air passed through the filter at a realistic ventilation system face velocity of $0.5 \mathrm{~m} \mathrm{~s}^{-1}$. Ozone was injected upstream of the filter, and its concentration was monitored continuously upstream and downstream of the filter, as well as in the incoming ambient air. Throughout the threemonth period, continuous measurements were made of the ambient temperature and humidity, as well as flow rate and pressure drop through the filter. The ozone removal efficiency was initially $96 \%$ and remained at $50 \%$ or higher for two and a half months. The estimated ozone removal capacity, before the efficiency dropped below $50 \%$, was 0.3 $\mathrm{g}$ ozone per gram carbon. The pressure drop of the air flowing through the ozone filter was $26 \mathrm{~Pa}$. Based on the size, efficiency, measured lifetime, and pressure drop of the ozone filter, it appears that ozone air cleaning may be practical in commercial air handling systems.
\end{abstract}




\section{BACKGROUND}

Ozone $\left(\mathrm{O}_{3}\right)$ is a highly reactive gaseous pollutant associated with adverse respiratory health effects. The US EPA has identified ozone as criteria pollutant for which the National Ambient Air Quality Standard is $80 \mathrm{ppb}$ (8-hr average). An extensive national air pollution control effort has been undertaken in the U.S. to reduce the emissions of pollutants that react photo-chemically in outdoor air to produce ozone. Despite this effort, outdoor ozone concentrations exceed EPA's standards in many U.S. cities. The ozone in outdoor air is the dominant source of indoor ozone within most buildings. Although indoor ozone concentrations tend to be $20 \%$ to $70 \%$ of outdoor concentrations (Weschler et al., 1989; Weschler et al., 1992; Weschler, 2000) most people's exposure to ozone occurs predominately indoors because people are inside buildings $90 \%$ of the time.

In addition to directly affecting health, ozone can react with a class of volatile organic compounds (VOCs) present in indoor air, producing new pollutants that are highly irritating (Weschler and Shields, 1999; Clausen et al., 2001). Reactions of ozone with some types of indoor materials, for example carpets (Weschler et al., 1992; Morrison et al., 1998; Morrison and Nazaroff, 2002) may also produce new irritating air pollutants.

The manipulation of ventilation rates is not a satisfactory means of controlling indoor ozone levels. Decreasing ventilation rates will generally result in lower indoor ozone concentrations, but concentrations of many indoor-generated pollutants will increase. On average, lower ventilation rates are associated with increased adverse health effects and diminished satisfaction with indoor air quality (Seppanen et al., 1999). In addition, reducing ventilation rates will lead to increased indoor concentrations of the irritating pollutants produced indoors from reactions of VOCs with ozone, because of the increased residence time for chemical reactions (Weschler and Shields, 2000). Increasing ventilation rates could reduce the concentrations of these reaction products; however, indoor ozone concentrations and ventilation energy use would both increase.

Air cleaning systems that remove ozone from incoming outdoor air could help to protect individuals from elevated outdoor ozone concentrations and from exposures to the irritant chemicals produced indoor as a result of reactions with ozone. The ASHRAE standard on ventilation for acceptable indoor air quality (ASHRAE 2001) states that incoming outdoor air should be treated to remove contaminants, including ozone, where outdoor air quality standards are exceeded.

Shields et al. (1999) and others have demonstrated that packed beds of granular activated carbon (GAC) designed to remove volatile organic compounds (VOCs) from airstreams can be effective as ozone air cleaners. These GAC beds typically consist of trays a few centimeters thick filled with granules of activated carbon. Multiple trays are installed in a zig-zag pattern in the cross-section of an air supply duct to increase the VOC sorption capacity, while limiting the increase in airflow resistance. While potentially quite effective as ozone air cleaners, these GAC systems are expensive, heavy, require considerable space, and usually impose substantial airstream pressure drops (for example 
$250 \mathrm{~Pa}$ ), and increase fan energy use. Consequently, activated carbon beds are not commonly used in buildings.

The GAC beds designed for removal of VOCs require large quantities of activated carbon because the VOC removal process is based on physical adsorption of the VOCs onto the activated carbon. With small quantities of carbon, the packed bed would quickly become saturated with VOCs and thus ineffective in further VOC removal. However, in contrast to the removal of VOCs, ozone is destroyed by chemical reactions with activated carbon. Consequently, in theory, air cleaning systems with much smaller quantities of activated carbon may be effective for ozone air cleaning, reducing costs and airstream pressure drops. This paper describes our exploration the feasibility of ozone air cleaning systems that may have lower pressure drops, weights and costs than conventional GAC air cleaners.

Since ozone reacts with and consumes the carbon in carbon-based air cleaners, the active elements must be replaced periodically rather than regenerated. The low cost of activated carbon and lack of potentially toxic additives can offset the cost of this effort. Potential activated carbon-based ozone configurations include:

- Trays of GAC, with grain size of several mm;

- Thin layers of smaller carbon grains incorporated into pleated fabric sandwiches;

- Non-woven mats or felts that incorporate carbon particles;

- Mats of activated carbon fibers;

- Carbon-impregnated open-cell foam; and

- Carbon honeycombs (also known as monoliths).

Any of these configurations could also be used with carbon that has been impregnated with reagent(s) for enhanced ozone destruction. Alternately, ozone can be removed by catalysts such as metal oxides. Most of the configurations listed above have been tried for catalytic removal of ozone.

The literature suggests that efficient catalytic ozone removal requires heating Pd- or Ptcontaining scrubber to at least $100{ }^{\circ} \mathrm{C}$. However, for practical and energy efficient ozone removal in ventilation systems, not only must the process take place at or very near ambient temperature, but also the active materials must be inexpensive and non-toxic. Promising catalytic candidates may be mixed reagent and inexpensive metal oxide materials such as carbon impregnated with iron and manganese oxides. A useful approach for the future is suggested by the encouraging results of Heisig et al. (1997).

\section{REVIEW OF PRIOR STUDIES}

In an eight-year evaluation of GAC beds for ambient ozone removal, Shields et al. (1999) passed air through GAC in two clean room ventilation systems and a laboratory test duct at $0.017 \mathrm{~m}^{3} \mathrm{~s}^{-1}$ air flow per $\mathrm{kg}$ of carbon $(17 \mathrm{cfm}$ air flow per $1 \mathrm{lb} . \mathrm{C})$. Face velocities ranged from 1.5 to $3.8 \mathrm{~m} \mathrm{~s}^{-1}$. Pressure drops were not reported. They found that 
efficiency was independent of upstream ozone concentration, but decreased reversibly during periods of high humidity. Protecting the GAC bed from ambient particulate matter led to higher efficiency at the start of the evaluation and slower decline in ozone removal efficiency.

Lee and Davidson (1999) compared ozone removal by activated carbon (AC) in four configurations. When possible they chose comparable materials from two manufacturers. They evaluated two materials designed for in use pleated configurations and three kinds of materials that normally mount perpendicular to air flow direction: non-woven mats, carbon fibers and carbon-impregnated foam. Small discs $\left(1.4 \mathrm{~cm}^{2}\right)$ of these airpermeable carbon-containing materials were stacked (without any pleating) to make each sample the same thickness $(1.3 \mathrm{~cm})$. They passed ozone at $120 \mathrm{ppb}$ in particle- and VOC-free air at $50 \% \mathrm{RH}$ through each material while monitoring pressure drop and ozone-removal efficiency over a period of $200 \mathrm{hr}$. Although they did not use GAC in these experiments, they tested pellets of a mixed manganese, copper and alumina catalyst with no external heating.

Table 1 compares the characteristics and efficiency of the ozone air cleaner configurations described above. Based on the data provided (Shields et al. 1999, Lee and Davidson 1999), we estimated the ozone removal capacities before efficiency dropped below $50 \%$. The capacity is expressed in two sets of units: 1) gram ozone removed per gram carbon, and 2) cubic meters of air treated per gram carbon assuming an inlet ozone concentration of $25 \mathrm{ppb}$ ). Estimates are omitted for the samples that did not remove at least $50 \%$ of the incoming ozone at the start of the ozone challenge.

Lee and Davidson (1999) found that the best performing materials were two of the four different types of thin fabric sandwiches that held small particles of AC. The sandwich materials showed higher capacity and lower pressure drops than the GAC used by Shields et al. (1999). These thin materials had been designed by the same manufacturer for use in a pleated configuration for removal of particles and vapors from the passenger compartments of high-priced automobiles. The remainder of the materials and configurations showed much lower capacities and sometimes higher pressure drops. The mats and foam impregnated with carbon did not perform well, nor did activated carbon fibers. No data were found in the archival literature for ozone removal by carbon honeycombs (monoliths) although some commercial products are now available.

Extrapolation of the published results for prediction of performance in actual ventilation systems must be undertaken with caution because of the variety of carbons in different grain sizes and material thicknesses. Lee and Davidson (1999) found that apparently similar materials from different manufacturers did not show the same capacities. Another concern is that Lee and Davidson conditioned the materials to $50 \%$ RH by equilibration with saturated solutions of $\mathrm{Ca}\left(\mathrm{NO}_{3}\right)_{2}$. Opila et al. (1989) found that this procedure generated enough $\mathrm{HNO}_{3}$ to affect indoor surface materials, suggesting that the aircleaning materials could be subject to oxidation during the equilibration step. 
Table 1. Ozone removal by activated carbon in several configurations, and a metal-based catalyst at room temperature.

\begin{tabular}{|c|c|c|c|c|c|c|}
\hline Configuration & $\begin{array}{l}\text { Granular } \\
\text { Bed }\end{array}$ & Pleated $^{\mathrm{a}}$ & Mat & Fiber & Foam & Catalyst \\
\hline Reference & \multirow{2}{*}{$\begin{array}{l}\text { Shields et } \\
\text { al., } 1999^{b}\end{array}$} & \multirow{2}{*}{\multicolumn{5}{|c|}{ Lee and Davidson, $1999^{b}$}} \\
\hline Parameter & & & & & & \\
\hline Face velocity, $\mathrm{m} \mathrm{s}^{-1}$ & $1.5-3.8$ & \multicolumn{5}{|c|}{2.5} \\
\hline $\begin{array}{l}\text { Capacity }(50 \% \\
\text { efficiency) }\end{array}$ & & & & & & \\
\hline g ozone/g C & $0.20^{\mathrm{d}}$ & $\begin{array}{l}0.0038- \\
0.69\end{array}$ & 0.000032 & 0.0041 & 0.00032 & 0.0037 \\
\hline$m^{3}$ air $/ g C$ & 6100 & $30-5800$ & 0.3 & 34 & 2.6 & 31 \\
\hline Pressure drop, $\mathrm{kPa}$ & $\begin{array}{l}\text { Not } \\
\text { available }\end{array}$ & $0.34-3.7$ & 0.15 & 2.2 & 0.13 & 0.63 \\
\hline Cost & Inexpensive & Moderate & Moderate & Moderate & Inexpensive & Moderate \\
\hline Handling ease & Heavy & Modular & Flexible & Unknown & Flexible & Heavy \\
\hline Disposal & C only & $\mathrm{C}+$ fibers & $\mathrm{C}+$ fibers & Carbon & $\mathrm{C}+\mathrm{PUF}$ & $\mathrm{Mn}, \mathrm{Al}, \mathrm{Cu}$ \\
\hline $\begin{array}{l}\text { Regenerative } \\
\text { potential for } \mathrm{O}_{3}\end{array}$ & Limited & Unlikely & Unlikely & Limited & Unlikely & Possible \\
\hline
\end{tabular}

${ }^{a}$ Flat section of materials used commercially in pleated configurations

${ }^{b}$ Sample area: $1.4 \mathrm{~cm}^{2}$; thickness: $1.3 \mathrm{~cm}$

${ }^{c}$ Annual average ozone concentration estimated as $25 \mathrm{ppb}$

${ }^{c}$ Stoichiometric limit: $2.7 \mathrm{~g} \mathrm{O}_{3} / \mathrm{g} \mathrm{C}\left(3 \mathrm{C}+2 \mathrm{O}_{3}=3 \mathrm{CO}_{2}\right)$

${ }^{d}$ Cleanroom 2; face velocity $2.3 \mathrm{~m} \mathrm{~s}^{-1}$.

${ }^{e}$ Estimated from Lee and Davidson data for $3 \mathrm{~mm}$ catalyst pellets.

\section{APPROACH}

Overview: A laboratory pilot study has been undertaken with the material that showed the most promise (high capacity and low pressure drop) based on the literature review and associated calculations. The best-performing air cleaner was a commercially available pleated filter that contained a thin layer of small activated carbon particles between two sheets of non-woven fibrous webbing. We will refer to this unit as the "ozone filter" although it is marketed for removal of VOCs from automobile passenger compartments.

The manufacturer supplied the pleated ozone filter as it is commercially available (3M Filtrete, Cabin Air Model R) and identified it as material B in the study of Lee and Davidson (1999). The ozone filter had a plastic frame $(18 \mathrm{~cm}$ x $25 \mathrm{~cm})$ that housed a strip of the carbon sandwich material (3-4 mm thickness, counting the webbing; $2.5 \mathrm{~cm}$ wide) that was folded into 20 pleats. The mass of carbon in the unit was extrapolated as $109 \mathrm{~g}$, from the amount of carbon removed from small areas of the same type of material. Lee and Davidson (1999) described material B as composed of $25 \times 45$ mesh coconut shell GAC, $1225 \mathrm{~m}^{2} \mathrm{~g}^{-1}$. 
To perform the test under fairly realistic conditions, the incoming air was filtered to remove most particles, but it was not conditioned to control ambient VOC concentrations, humidity or temperature. For three months ozone (at total average concentration of 112.5 ppm) in ambient air passed through the air cleaner at a realistic ventilation system face velocity.

Ozone was produced from oxygen with a commercial generator, introduced at about 100 $\mathrm{ppb}$, and the resulting ozone concentrations were monitored continuously upstream and downstream of the ozone filter, as well as in the incoming particle- filtered ambient air. Throughout the three-month period continuous measurements were made of the ambient temperature and humidity, as well as flow rate and pressure drop through the ozone filter.

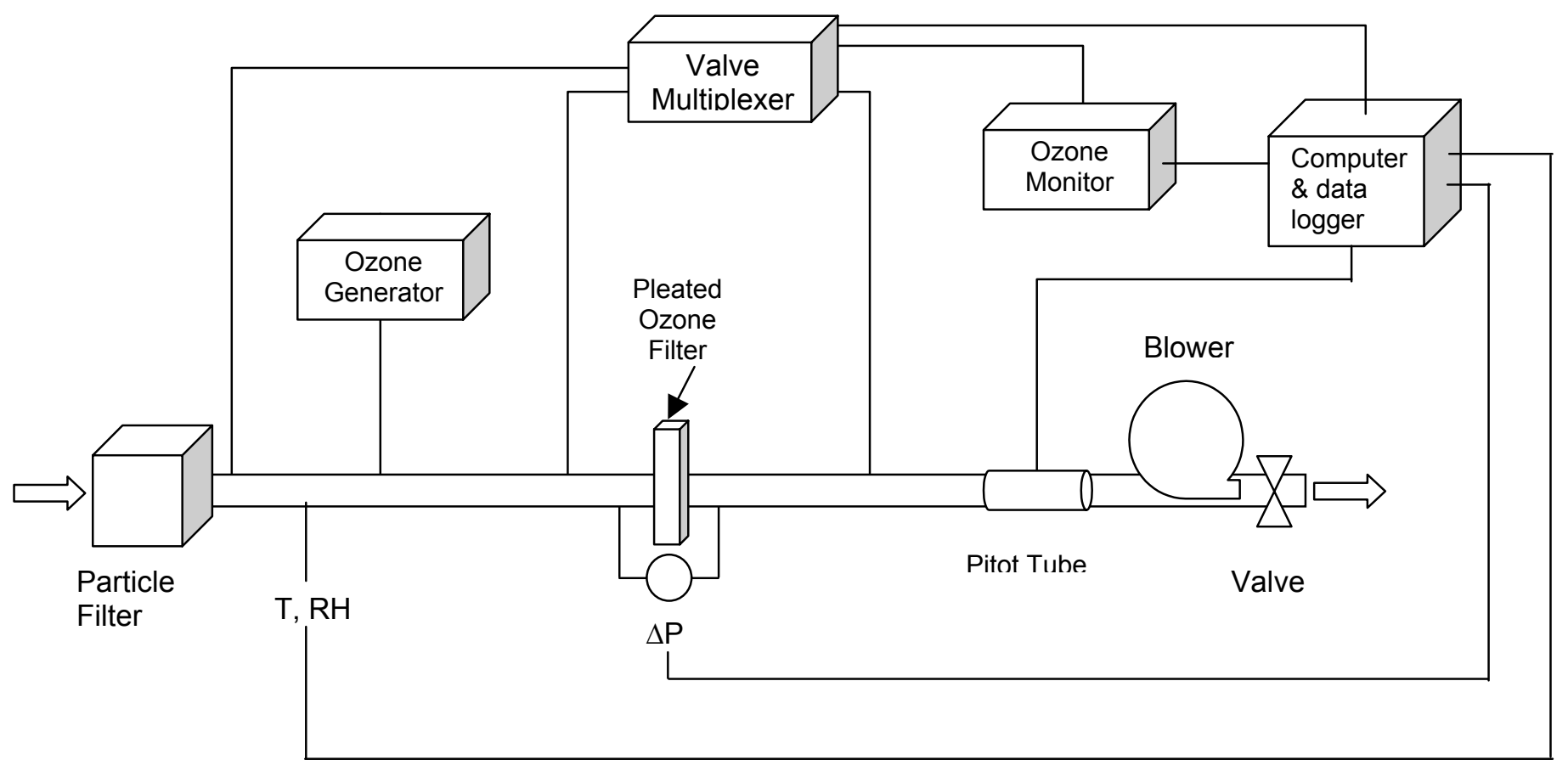

Figure 1. Schematic diagram of the test duct of the experimental system.

A schematic diagram of the experimental system is shown in Figure 1. The ventilation duct was assembled from Teflon-lined tubing (1/8 in I.D. and 3/16 in O.D.) and Kynar fittings (1/8 in I.D.). The ozone filter (Filtrete ${ }^{\mathrm{TM}}$ Cabin Air Filter, 3M Filtration Products, in the manufacturer's mount) was installed perpendicular to the flow direction in a sheet metal box that had been lined with Teflon sheets and sealed with adhesive designed for use with Teflon. Ambient particulate matter was removed from the incoming air by a filter rated at $95 \%$ efficiency for $0.3 \mu \mathrm{m}$ diameter particles. A blower downstream of the ozone filter operated at $0.023 \mathrm{~m}^{3} \mathrm{~s}^{-1}(49.5 \mathrm{cfm})$. The face velocity for the ozone filter was 
$0.52 \mathrm{~m} \mathrm{~s}^{-1}$, which is typical of a face velocity at a filter bank in a building ventilation system. Flow rates were measured with Pitot tubes and a calibrated pressure transducer. Pressure was measured upstream and downstream of the ozone filter.

Ozone was produced from a cylinder of oxygen by a generator (Ozone Services, Model GE30, Burton, BC, Canada: corona discharge design, modified for low flow) and bled into the incoming air upstream. Ozone concentrations were measured with two UV photometric instruments (Dasibi, Model 1003-AH, Glendale, CA). The monitors were calibrated at the facilities of the California Air Resources Board in Sacramento.

Before installation of the ozone filter, the duct was conditioned with ozone at $100 \mathrm{ppm}$ until the concentration downstream had stabilized and agreed with the upstream concentration to within a few percent. Approximately every other day, zero ozone concentration was established by connecting a separate GAC filter to the ambient air inlet of the monitor. To establish and verify the addition of ozone equivalent to $100 \mathrm{ppm}$ in the inlet airstream, the GAC filter was temporarily connected to the filtered ambient air supply so that the upstream air contained only the generated ozone. The added ozone mixing ratio was stable to better than $2 \%$. That means that the generator contributed 100 $\pm 2 \mathrm{ppm}$ of the total upstream ozone concentration. The contribution from ambient air varied much more.

For the first three weeks of exposure, both ozone monitors were used, giving separate continuous measurements upstream and downstream of the ozone filter. For the next three weeks a programmable six-position multiplexing valve (Valco Instruments, Model C45-9786E, Houston, TX) operated on a 20 min cycle to allow cyclical ozone monitoring in the filtered ambient air upstream of the location of ozone addition, as well as immediately upstream and downstream of the ozone filter. After six weeks an independently controlled auxiliary air cleaner duct was put into use, in addition to the main duct described above, for evaluation of potential ozone catalysts, and the valve was operated on a 10 min cycle to accommodate two more ozone measurement positions. (Results from the auxiliary line are not reported here.) The ozone monitor(s) reported one-minute averages to the data logging system that also recorded valve position, temperature, relative humidity, flow rates and pressure drops across the air cleaner. Binary data files were converted to text files and then processed using Microsoft Access to sort the ozone data by valve position and generate 30 min averages for each parameter. The ozone removal efficiency was calculated from the data as the percentage of upstream ozone that was removed by the ozone filter, $100 *\left(1-\left\{\left[\mathrm{O}_{3}\right.\right.\right.$ Downstream $] /\left[\mathrm{O}_{3}\right.$ Upstream $\left.\left.]\right\}\right)$.

\section{RESULTS}

Results for three months ozone filtration are shown in Figure 2. Thirty minute averages of the upstream and downstream ozone concentrations, ozone removal efficiency, ambient temperature and relative humidity are plotted versus date and time. 

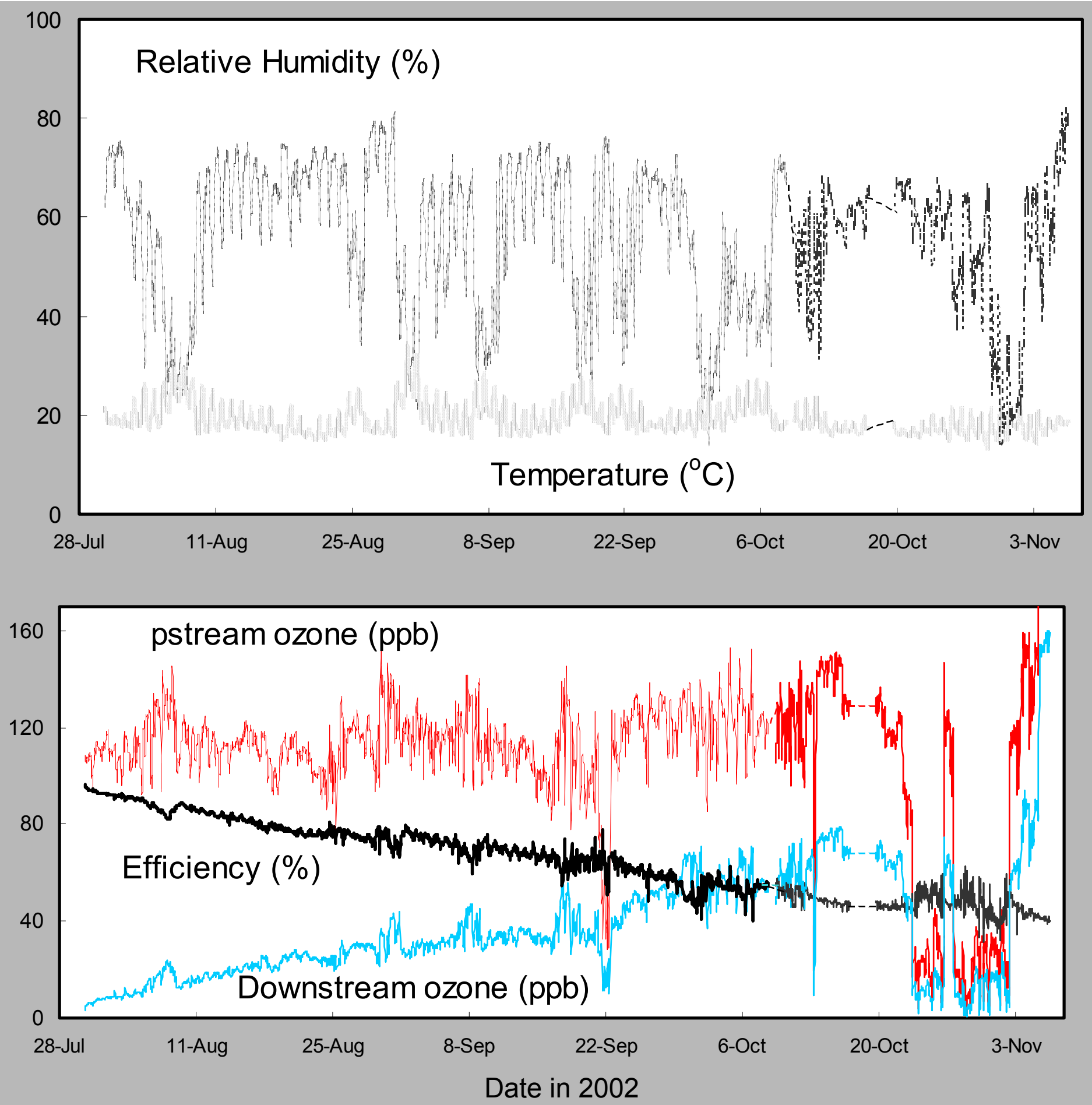

Figure 2. Performance data (30 min averages) for the first three months of continuous exposure of the pleated ozone filter to ozone at $113 \pm 13 \mathrm{ppb}$. 
The diurnal cycle of temperature and RH shows clearly in the upper part of Figure 2. The upstream ozone record reflects the sum of ambient and generated concentrations. Since the generated ozone concentration was much more stable than the ambient ozone concentrations, the profile reflects changing ambient conditions, as well as measurement variability. Ambient ozone concentrations (recorded but not shown separately in Fig. 2) typically increased during periods of hot dry ambient conditions. Instrumental noise increased twice, corresponding to the implementation of more complex valve-switching protocols with reduced cycling time. The temporary substantial drop in upstream ozone concentration near the end of the second month occurred when the auxiliary duct was first operational. Near the end of the three-month period, the upstream ozone concentration decreased temporarily while the generator was serviced.

Figure 2 shows that the ozone filter had an initial efficiency of $96 \%$. By the seventh day of exposure the filter efficiency was $90 \%$. The efficiency was 77,60 and $40 \%$ at the end of the first, second and third months respectively. The efficiency had dropped to $50 \%$ by 75 days ( $2 \frac{1}{2}$ months) exposure.

Table 2 compares the performance of the ozone filter (as used in this study) with the GAC used by Shields and Wechsler (1999) and flat layers of the same sandwich material tested by Lee and Davidson (1999). The observed long-term capacity is in the same range as predicted by extrapolating from the short term data of Lee and Davidson (1999). The capacity of the mounted pleated carbon sandwich more closely matches the data for Lee and Davidson's material A than it does for material B. Both materials were supplied by the same manufacturer.

Table 2. Performance of GAC and carbon sandwich for ozone removal: Capacity at 50\% efficiency and pressure drop

\begin{tabular}{|c|c|c|c|c|}
\hline Configuration & $\begin{array}{l}\text { Granular Bed } \\
\text { Shields et al., } \\
1999^{\text {a }}\end{array}$ & \multicolumn{2}{|c|}{$\begin{array}{l}\text { Flat Layers of } \\
\text { Carbon Sandwich } \\
\text { Lee and Davidson, } \\
1999\end{array}$} & $\begin{array}{l}\text { Pleated Carbon } \\
\text { Sandwich, this } \\
\text { study }\end{array}$ \\
\hline Parameter & & $\mathrm{A}$ & $\mathrm{B}$ & This study \\
\hline Face velocity, $\mathrm{m} \mathrm{s}^{-1}$ & 2.3 & 2.5 & 2.5 & 0.52 \\
\hline $\begin{array}{l}\text { Capacity }(50 \% \\
\text { efficiency) } \\
\text { g ozone } / \mathrm{g} \mathrm{C} \\
m^{3} \text { air } / g C\end{array}$ & $\begin{array}{l}0.20 \\
6100\end{array}$ & $\begin{array}{l}0.34^{\mathrm{d}} \\
2800^{d}\end{array}$ & $\begin{array}{l}0.69^{\mathrm{d}} \\
5800^{d}\end{array}$ & $\begin{array}{l}0.33 \\
1370\end{array}$ \\
\hline Pressure drop, $\mathrm{kPa}$ & Not available & 0.34 & 0.58 & 0.026 \\
\hline
\end{tabular}


During the exposure period the pressure drop through the ozone filter averaged $26 \mathrm{~Pa}$. This was much lower than observed by Lee and Davidson who used six layers of the same material in a filter holder. The dependence of the pressure drop on face velocity measured in this study is shown in Fig 3. The results show that doubling the face velocity from 0.5 to $1.0 \mathrm{~m} \mathrm{~s}^{-1}$ caused the pressure drop to increase to $60 \mathrm{~Pa}$.

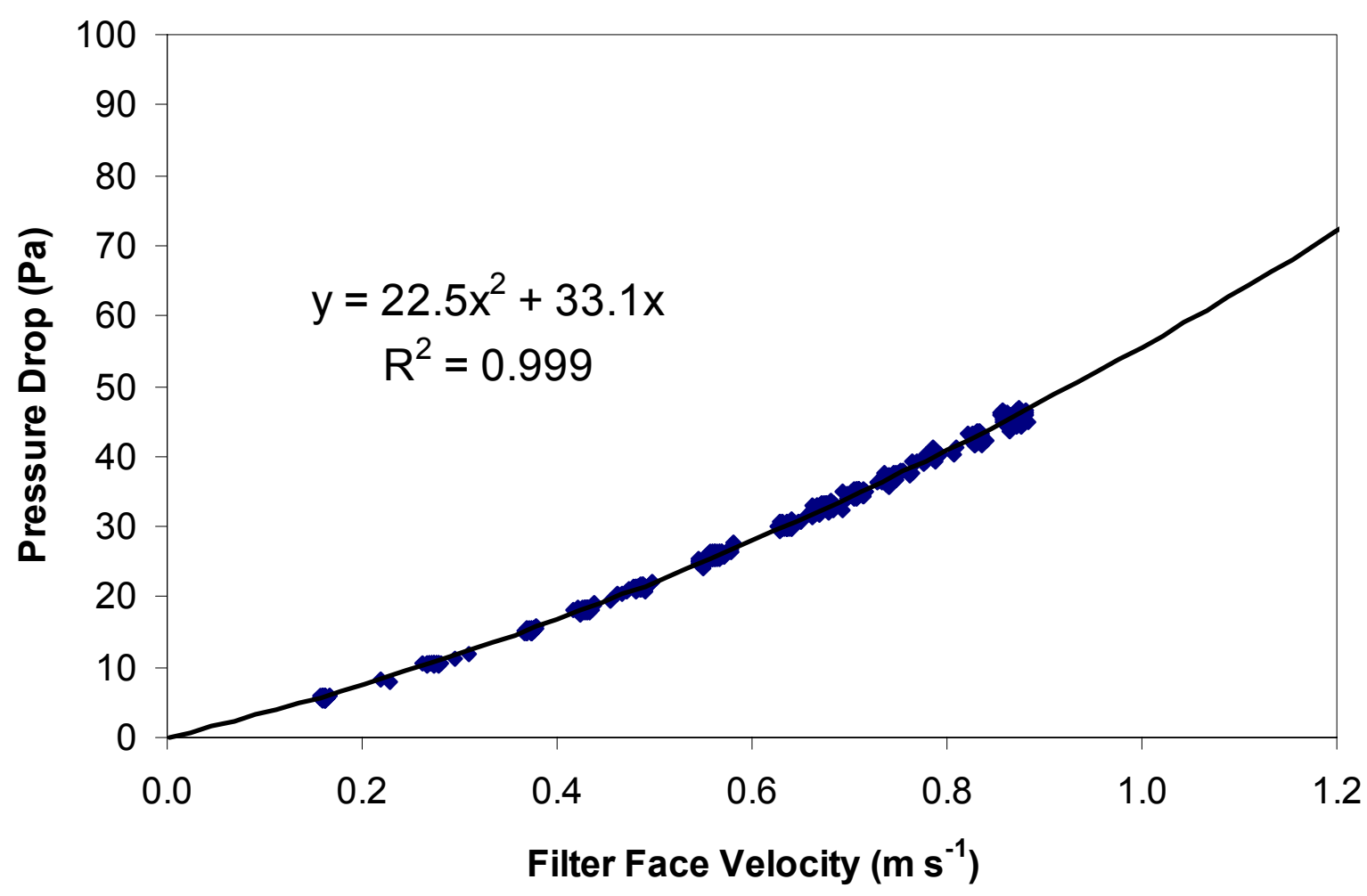

Figure 3. Pressure drop across the ozone filter vs. face velocity

\section{DISCUSSION}

In size and appearance, the ozone filter used in these tests resembles a $2.5 \mathrm{~cm}$ (1 inch) pleated particle filter that is used commonly in packaged air handling units; hence, the ozone filter size and configuration are clearly practical. The ozone filter lifetime was also sufficient for practical applications. The efficiency was maintained at approximately $50 \%$ or higher during three months of continuous operation with an inlet ozone concentration of $113 \mathrm{ppb}$, which is considerably higher than the time-average ozone concentration (roughly $25 \mathrm{ppb}$ ) expected even in polluted urban areas. In practice, commercial building air handlers are often operated only about $50 \%$ time, i.e., they are turned off during the night time and on weekends, thus, the three-month test period is equivalent to approximately six months of normal operation with an inlet ozone concentration that is roughly four times the average concentration expected in practice. 
When $2.5 \mathrm{~cm}$ thick particle filters are used in air handlers, they are normally replaced every few months which is less that the anticipated life of the ozone filter.

The pressure drop of the ozone filter was only $26 \mathrm{~Pa}$. At twice the face velocity the pressure drop would be about $60 \mathrm{~Pa}$. These values are small relative to the normal range of total airstream pressure drops (250 to $500 \mathrm{~Pa}$ ) in supply air for commercial systems. Thus, the pressure drop of the ozone air cleaner should not be objectionable.

Unlike the tests of Lee and Davidson (1999) this pilot study used an inlet airstream that contained normal outdoor-air VOCs. Thus, the pilot study confirmed that the presence of VOCs, at least those present in the study, did not prevent ozone removal.

Based on the size, efficiency, measured lifetime, and pressure drop of the ozone filter, it appears that ozone air cleaning may be practical in commercial air handling systems. We do not have an estimate of the cost of the ozone filter with large scale production of units sized for commercial buildings (as opposed to production of small filters for luxury automobiles); however, we would not expect the cost to be prohibitive.

If higher ozone removal efficiency and/or longer filter lifetime were desired without increasing the airstream pressure drop, it would be relatively simple to increase the thickness of the ozone filter beyond $2.5 \mathrm{~cm}$. Particle filters for commercial buildings have a thickness of 2.5 to more than $30 \mathrm{~cm}$.

Despite the very promising results of this pilot study, additional tests should be performed before drawing final conclusions about filter performance in actual practice. The influence of lower inlet ozone concentrations, higher humidity, and different air temperatures should be evaluated. Also, ozone filter lifetime should be assessed with a more typical (lower efficiency) particle filter located upstream. Finally, the ozone removal performance should be evaluated with no upstream particle filter.

\section{CONCLUSIONS}

This pilot study strongly suggests that ozone air cleaning can be practical in commercial air handling systems; however, further tests are needed to assess air cleaner performance under a wider range of conditions.

\section{ACKNOWLEDGEMENTS}

The authors thank Michael Strommen of 3M Filtration Products for providing the Filtrete $^{\mathrm{TM}}$ Cabin Air Filters. The authors also thank Al Hodgson for useful discussions and Tosh Hotchi for assistance with data analysis, as well as calibration of the ozone monitors. The assistance of Matt Quok and Ken Stroud of the California Air Resources Board is appreciated. This work was supported by the Assistant Secretary for Energy 
Efficiency and Renewable Energy, Building Technologies Program of the U.S. Department of Energy under contract No. DE-AC03-76SF00098.

\section{REFERENCES}

ASHRAE, Ventilation for acceptable indoor air quality, ASHRAE Standard 62-2001, American Society of Heating, Refrigeration and Air-Conditioning Engineers, Inc., Atlanta GA (2001)

P.A. Clausen, C.K. Wilkins, P. Wolkoff, G.D. Nielsen, Chemical and biological evaluation of a reaction mixture of $R-(+)$-limonene/ozone: Formation of strong airway irritants, Environ. Intern., 26, 511-522 (2001).

C. Heisig, W. Zhang and S.T. Oyama, Decomposition of ozone using carbon-supported metal oxide catalysts, Appl. Catal. B: Environ. 14, 117-129 (1997).

P. Lee and J. Davidson, Evaluation of activated carbon filters for removal of ozone at the ppb level, Am. Ind. Hyg. J., 60, 589-600 (1999).

G.C. Morrison, W.W. Nazaroff, J. Alejandro Cano-Ruiz, A.T. Hodgson and M.P. Modera, Indoor air quality impacts of ventilation ducts: Ozone removal and emissions of volatile organic compounds, J. Air and Waste Manage. Assoc., 48, 941-952 (1998).

G.C. Morrison and W.W. Nazaroff, Ozone interactions with carpet: Secondary emissions of aldehydes, Environ. Sci. Technol., 36, 2185-2192 (2002).

R.J. Opila, C.J. Weschler and R. Schubert, Acidic vapors above saturated salt solutions commonly used for control of humidity, IEEE Trans. Comp., Hybrids, Manuf. Technol., 12, 114-120 (1989).

O.A. Seppanen, W.J. Fisk and M.J. Mendell, Association of ventilation rates and $\mathrm{CO}_{2}$ concentrations with health and other human responses in commercial and institutional buildings, Indoor Air, 9, 226-252 (1999). LBNL-43334

H.C. Shields, C.W. Weschler and D. Naik, Ozone removal by charcoal filters after continuous extensive use (5 to 8 years), Proceedings of the 8th International Conference on Indoor Air Quality and Climate, Indoor Air 99, Edinburgh, Scotland, Aug. 8-13, 1999, Vol. 4, p. 49-54.

C.J Weschler, A. T. Hodgson, and J. D. Wooley, Indoor Chemistry: Ozone, volatile organic compounds and carpets, Environ. Sci. Technol., 26, 1200-1210, (1992).

C.J. Weschler, H.C. Shields and D. V. Naik, Ozone removal efficiencies of activated carbon filters after more than three years of continuous service, ASHRAE Trans, Symposia, 100, 1121-1129 (1994). 
C.J. Weschler and H.C. Shields, Indoor ozone/terpene reactions as a source of indoor particles, Atmos. Environ., 33, 2307-2318, (1999).

C.J. Weschler, Ozone in indoor environments: concentration and chemistry, Indoor Air, 10, 269-288 (2000).

C.J. Weschler and H.C. Shields, The influence of ventilation on reactions among indoor pollutants: modeling and experimental observations, Indoor Air, 10, 92-100, (2000). 